\title{
Traumatic Impaction of Unusual Foreign Body in a 10-year-old Boy's Mouth: A Case Report
}

\author{
Gaurav Gupta ${ }^{1}$, DK Gupta ${ }^{2}$, Manohar Bhat ${ }^{3}$, Neelja Gupta ${ }^{4}$, Priyanka Gupta ${ }^{5}$, Saakshe Wadhwa ${ }^{6}$
}

\begin{abstract}
Placing objects in the mouth by children get accidentally implanted in the oral cavity, ingested, or aspirated. The incidence of foreign bodies is usually higher in the zone of head and neck than other regions of the human body. Usually, foreign bodies are symptomatic and signs of inflammation pain and purulent discharge are shown. This paper describes an unusual case of traumatic foreign body (pen cover) accidently moved in the retromolar area causing recurrent facial swelling, purulent discharge, and reduced mouth opening.

Keywords: latrogenic foreign body, Oral cavity, Traumatic foreign body.

International Journal of Clinical Pediatric Dentistry (2020): 10.5005/jp-journals-10005-1799
\end{abstract}

\section{INTRODUCTION}

There are many reasons by which foreign bodies can be ingested, inserted into a body cavity, or deposited into the body by traumatic or iatrogenic injury. Common causes for traumatic foreign bodies can be motor vehicle accidents, assaults, and bullet wounds. ${ }^{1}$ The size and the type of object, anatomical relationship of the foreign body to vital structures, and difficult access toward it are the challenges for the surgeon to deal with. ${ }^{2}$ Metallic objects ${ }^{3}$ and restorative materials such as amalgam, wooden stick, ${ }^{4}$ broken instruments, obturation materials, and needles are considered as foreign bodies. ${ }^{5}$ These cases are often diagnosed accidentally on radiographic examination ${ }^{6}$ or pain and signs of inflammation with purulent discharge are associated with it. ${ }^{7}$ Due to this, it is necessary to identify and remove it from the tissue. ${ }^{8}$

Proper diagnosis should be done to find the exact location of foreign bodies before its removal, and for this, proper investigation should be done. Depending on the composition and exact location of the foreign body, computed tomography (CT) scans, plain radiographs, ultrasound, and magnetic resonance imaging (MRI) can be done. ${ }^{9,10}$ Due to the migration risk to adjacent areas, these should be immediately done at the time of surgery. ${ }^{11,12}$

This paper describes a case of facial trauma by a blunt object (pen cover) accidently moved in the retromolar area causing recurrent facial swelling, purulent discharge, and reduced mouth opening.

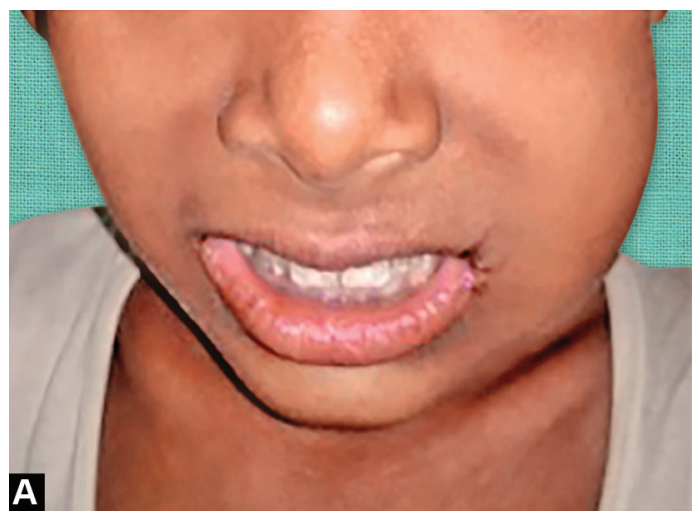

'Department of Pedodontics, Jaipur Dental College, Maharaj Vinayak Global University, Jaipur, Rajasthan, India; Private Practice, Jaipur, Rajasthan, India

2,4,6 Private Practice, Jaipur, Rajasthan, India

${ }^{3}$ Department of Pedodontics, Jaipur Dental College, Maharaj Vinayak Global University, Jaipur, Rajasthan, India

${ }^{5}$ Department of Pediatric and Preventive Dentistry, RUHS College of Dental Science, Jaipur, Rajasthan, India

Corresponding Author: Gaurav Gupta, Department of Pedodontics, Jaipur Dental College, Maharaj Vinayak Global University, Jaipur, Rajasthan, India; Private Practice, Jaipur, Rajasthan, India, Phone: +91 9829560606, e-mail: dr.gauravgupta99@gmail.com

How to cite this article: Gupta G, Gupta DK, Bhat M, et al. Traumatic Impaction of Unusual Foreign Body in a 10-year-old Boy's Mouth: A Case Report. Int J Clin Pediatr Dent 2020;13(4):433-436.

Source of support: Nil

Conflict of interest: None

\section{Case Description}

A 10-year-old boy was referred to us with the complaint of recurrent swelling on the left side of the face along with purulent discharge and reduced mouth opening since 3 months (Fig. 1). The swelling got relieved on taking antibiotics and anti-inflammatory medicines but reoccurred again. There was no relevant past medical history.

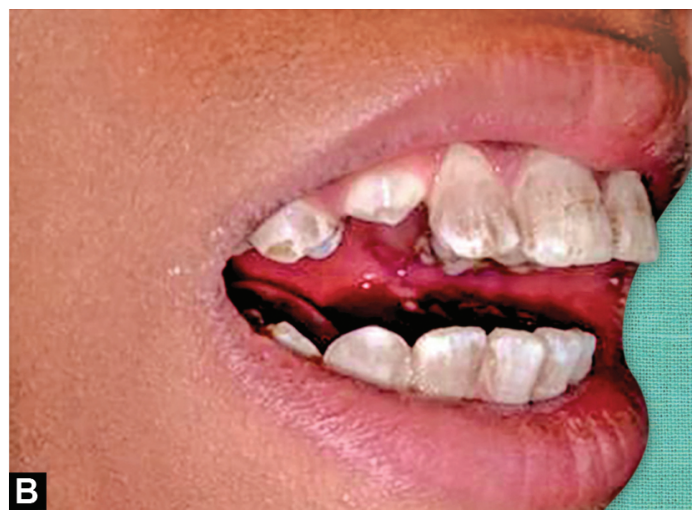

Figs 1 A and B: (A) Facial swelling on the left side of the face; (B) Reduced mouth opening

(-) The Author(s). 2020 Open Access This article is distributed under the terms of the Creative Commons Attribution 4.0 International License (https://creativecommons. org/licenses/by-nc/4.0/), which permits unrestricted use, distribution, and non-commercial reproduction in any medium, provided you give appropriate credit to the original author(s) and the source, provide a link to the Creative Commons license, and indicate if changes were made. The Creative Commons Public Domain Dedication waiver (http://creativecommons.org/publicdomain/zero/1.0/) applies to the data made available in this article, unless otherwise stated. 
No history of trauma was prevailed. On clinical examination, we could only acknowledge the mobility of second primary molar which was about to exfoliate as mouth opening was reduced. There was no sign of caries on the first permanent molar. Nothing was acquired from oral examination, so orthopantomogram (OPG) was advised.

OPG revealed no signs of carious exposure, impacted teeth, or cyst/tumor in that area (Fig. 2); therefore, ruling out to be hard/bony

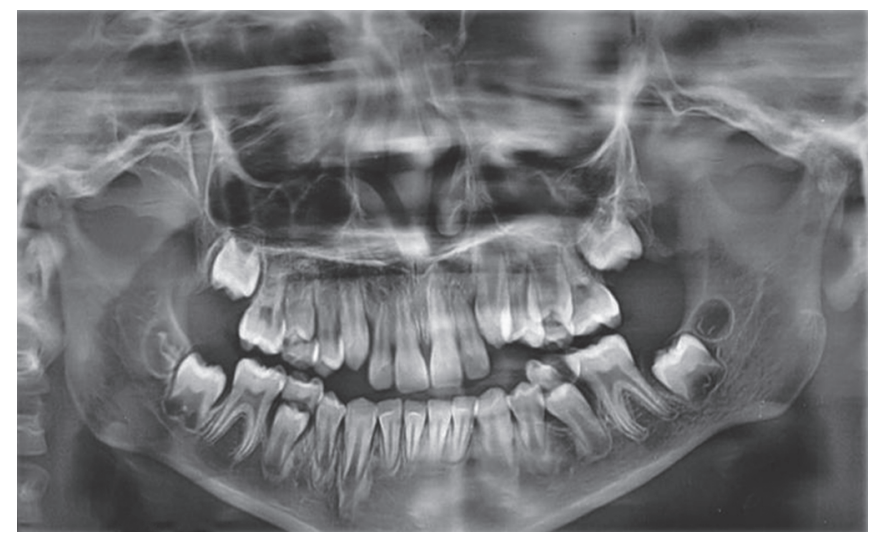

Fig. 2: Orthopantomogram showing no signs of carious exposure tissue pathology, soft tissue pathology was presumed. Then, the patient was advised for MRI. Magnetic resonance imaging revealed a strange foreign body which was cylindrical in appearance situated near the retromolar area (Fig. 3).

Due to lack of compliance and reduced mouth opening, it was planned to remove the foreign object under general anesthesia set-up. In the procedure, a vestibular incision is given from the region of first permanent molar to the anterior border of ramus. Mucoperiosteal flap is raised and blinded, but careful dissection is done in the region of pterygomandibular space so as to avoid any unintentional injuries (Figs 4 to 6).

We startled as we felt a hard structure, which was carefully separated from the adjacent vital structures such as inferior alveolar nerve and vessels, lingual nerve, and vessels. After elevation with the help of Ellis tissue-holding forceps, a strange foreign body was taken out which was found to be a cap of a plastic ball pen (Figs 7 to 9). The wound was thoroughly irrigated with normal saline, and primary closure was done by 3.0 black silk (Fig. 10). Routine medications and postoperative instructions were given.

Reduced mouth opening was completely resolved in 7 days (Fig. 11). There was complete recovery without any medication after 5 days. Oral hygiene instructions were given.

Further, when the patient was enquired regarding the foreign body, he had a faint memory of fight among the classmates around
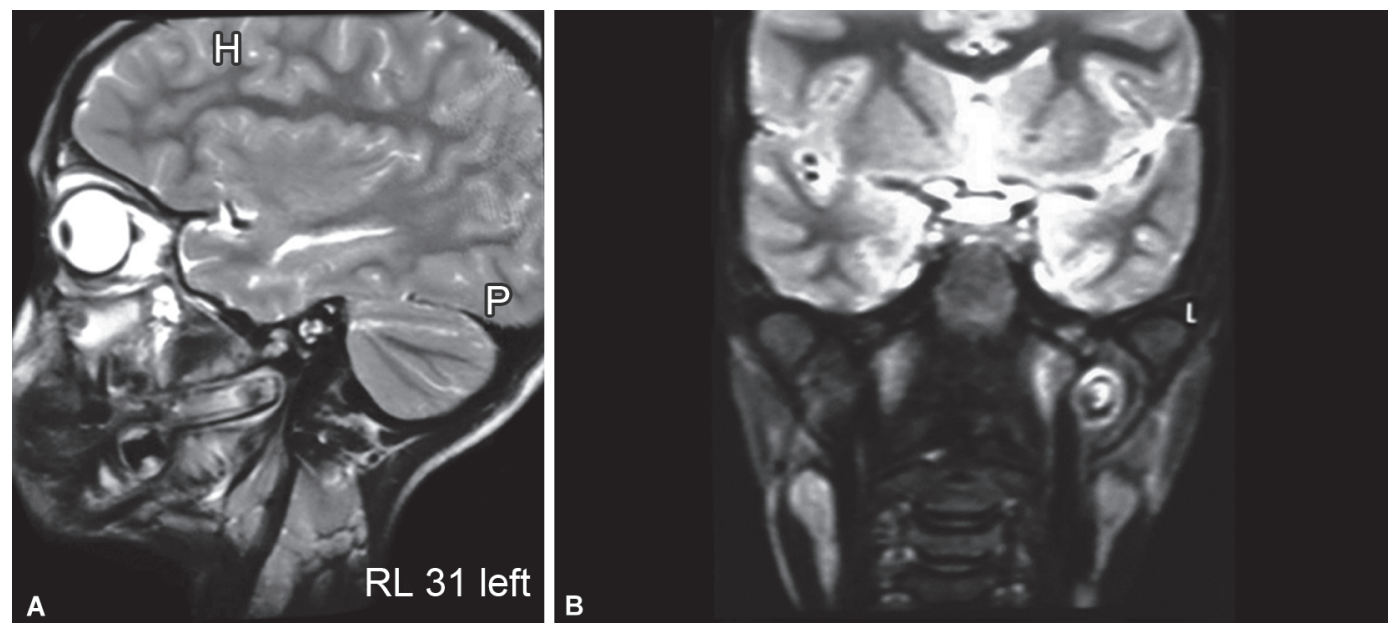

Figs $3 \mathrm{~A}$ and B: Magnetic resonance imaging showing the presence of a strange foreign body

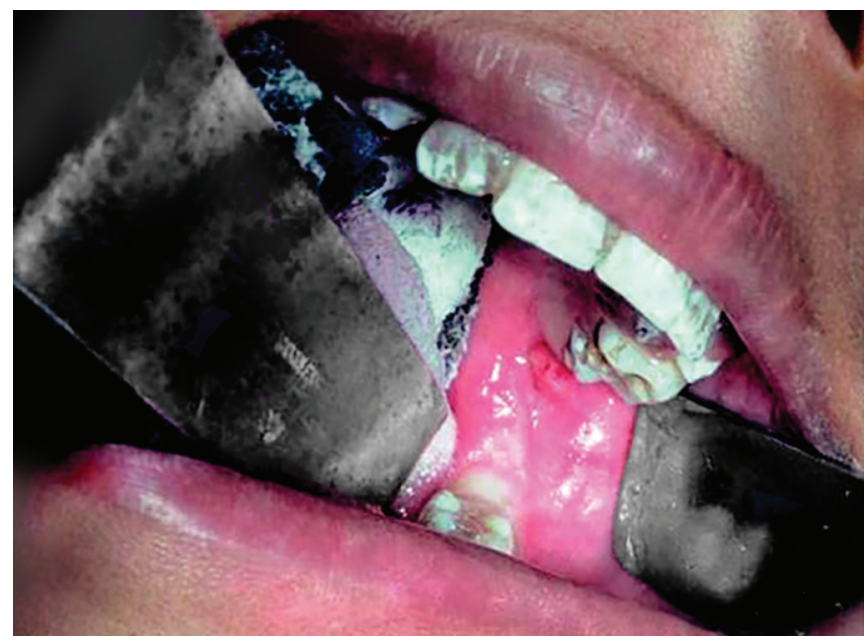

Fig. 4: No sign of intraoral inflammation

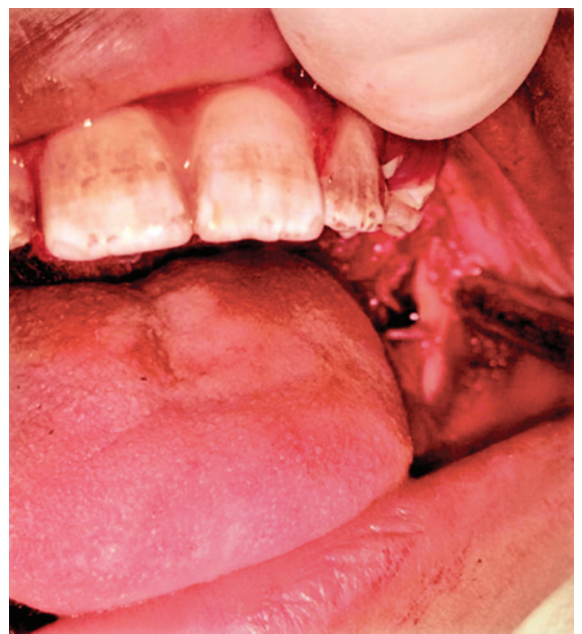

Fig. 5: Incision given and mucoperiosteal flap elevated 


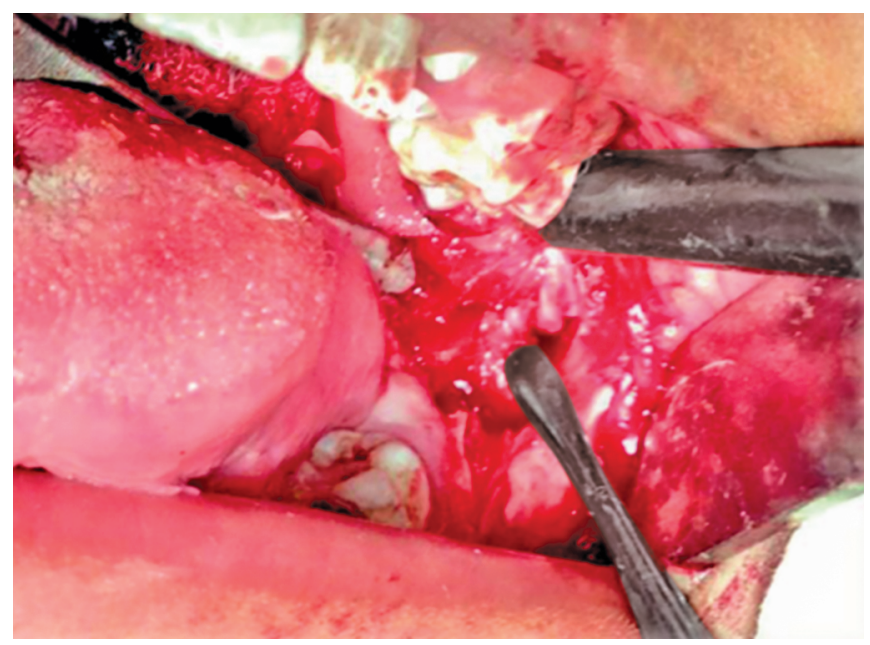

Fig. 6: Blind dissection

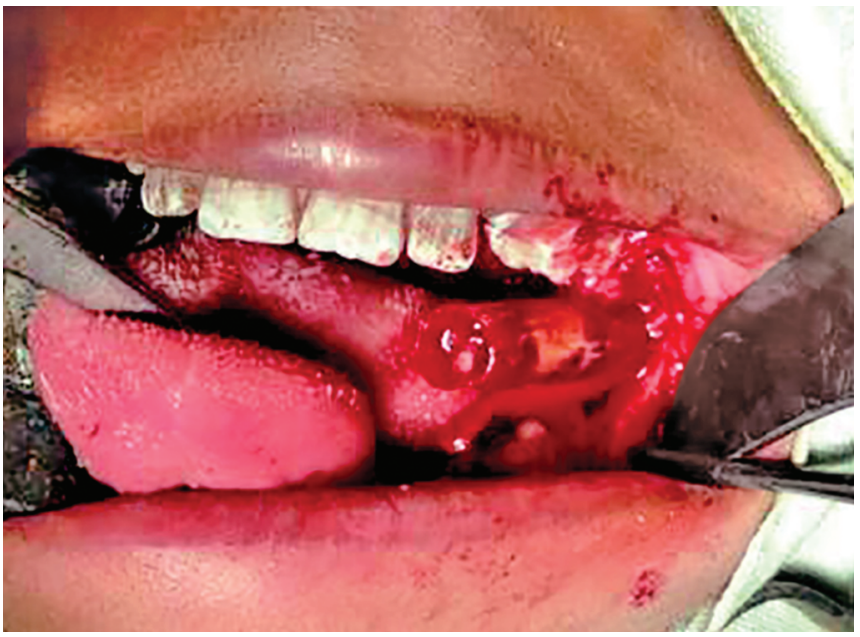

Fig. 8: Careful elevation of foreign body

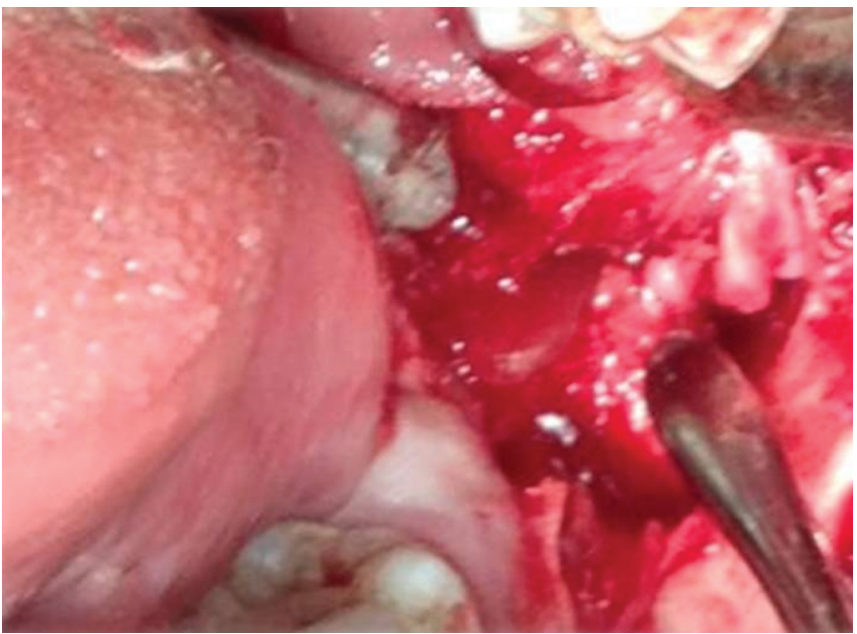

Fig. 10: Cleaning and irrigation of wound

3.5 months back. He had slight bleeding at that time which stopped there and then only with not much pain. The child because of fear did not tell anything to anyone.

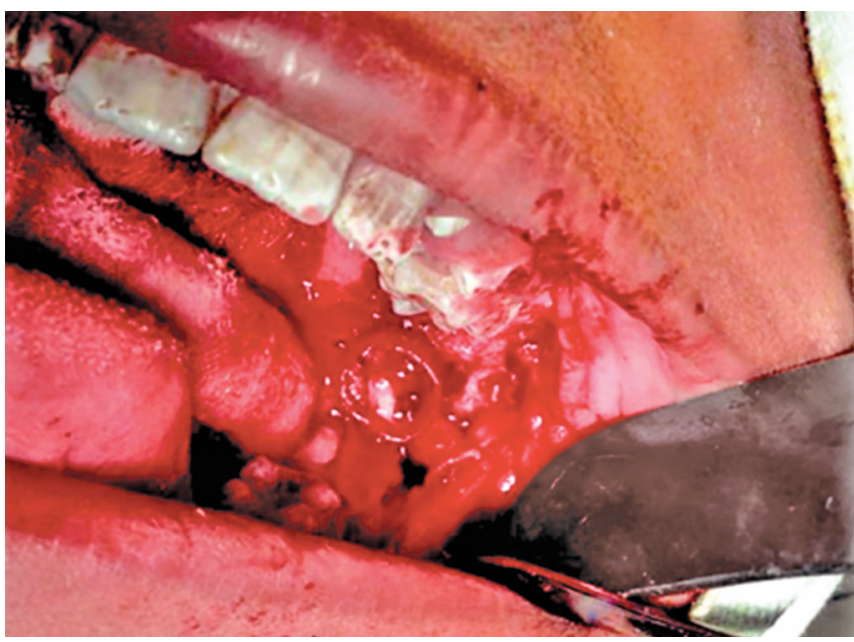

Fig. 7: Emergence of foreign body

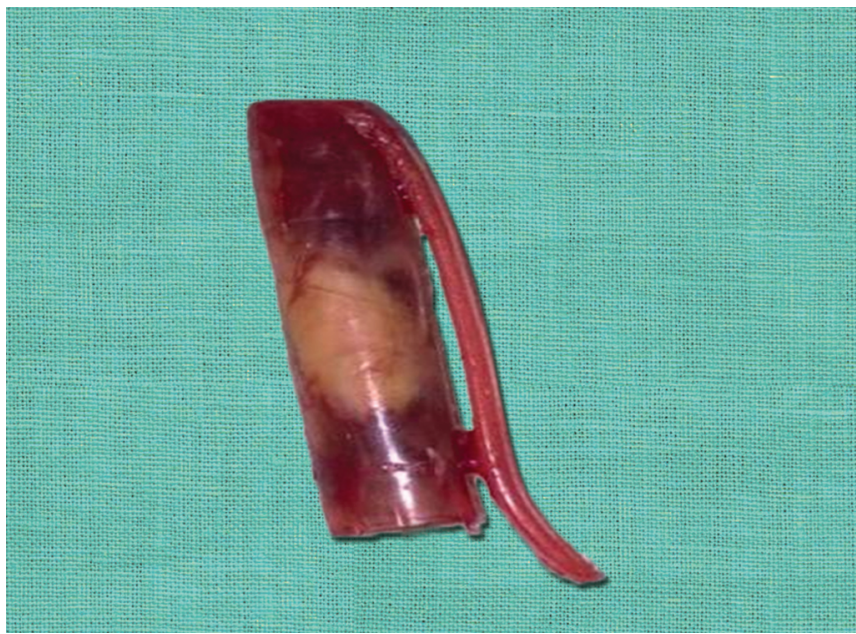

Fig. 9: Foreign body "cover of plastic ball pen" with granulation tissue

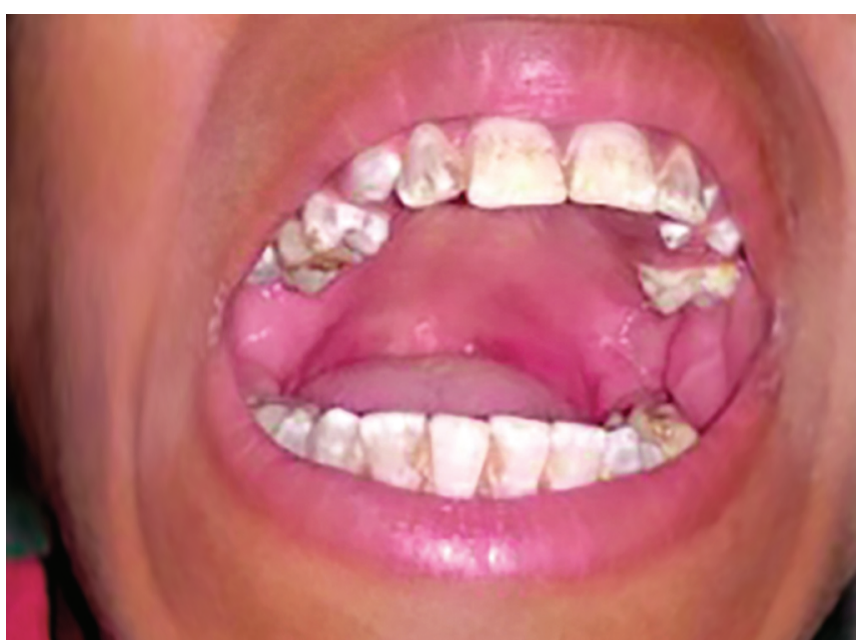

Fig. 11: Immediate mouth opening after 7 days

Surprisingly, the child himself did not realize that something had gone inside the wound after that fight. Later, after 20 days, swelling and reduced mouth opening happened. The child could 
not relate his extra oral swelling with that incident. Therefore, due to lack of right investigation, the situation worsened leading to scarring and fibrosis of the tissues.

\section{Discussion}

Either by traumatic injury or iatrogenically, foreign bodies may get deposited in the oral cavity which can be due to motor vehicle accidents, bullet wounds, and glass pieces. These are the most frequently reported traumatic foreign bodies. ${ }^{13}$

Clinically, these impacted foreign bodies are difficult to detect; hence, they pose a diagnostic challenge. Depending on foreign bodies' inherent radio density and proximity with the tissue in which they are embedded, they may be visualized on plain radiographs based on their ability to attenuate rays. ${ }^{14}$ Metallic objects are opaque on radiographs, unless made of aluminum. Foreign bodies such as stones, displaced pieces of teeth, various metals, and glass can be revealed on plain radiograph and CT. In our case report, the foreign body (pen cover) was visible in cylindrical shape through MRI and was radio-opaque.

Removal of these foreign bodies is mandatory even if the patient is asymptomatic, as these objects usually lead to secondary infection, with abscess and fistula formation. ${ }^{15}$ The composition and location of the foreign bodies can vary considerably as superficial and penetrating foreign bodies depending on the type of trauma. Usually easy to remove if seen are the superficial bodies and those which are more difficult to remove are penetrating foreign bodies. ${ }^{16}$ To determine whether the foreign body is near vital structures or not is necessary. In most of the cases, patients possessed with oral pain and signs of inflammation with purulent discharge. Rarely in the dental literature, there are reports of asymptomatic foreign bodies. ${ }^{12,17}$ In this case report, the foreign body was penetrating and was presented near the retromolar area.

Due to a misdiagnosis or the absence of symptoms, the prompt removal of foreign bodies from the body may not occur. ${ }^{18}$ The patient sought treatment only when he suffered from pain, swelling, purulent discharge, and limitation of mouth opening, i.e., when situation worsened.

\section{Conclusion}

Primary complaint of the patient was recurrent facial swelling, and on routine intraoral examination, a neglected, asymptomatic foreign body was revealed after 3 months. This case report emphasizes that to avoid local and systemic complications due to the foreign body, it is important to take thorough and systematic dental examination. On trismus (reduced mouth opening) complaint cases, it should be included in the differential diagnosis, especially in patients with recent past history of trauma.

\section{References}

1. de Santana Santos T, Melo AR, de Moraes HH, et al. Impacted foreign bodies in the maxillofacial region-diagnosis and treatment.J Craniofac Surg 2011;22(4):1404-1408. DOI: 10.1097/SCS.0b013e31821cc53e.

2. Holmes PJ, Miller JR, Gutta R, et al. Intraoperative imaging techniques: a guide to retrieval of foreign bodies. Oral Surg, Oral Med, Oral Pathol, Oral Radiol Endodontol 2005;100(5):614-618. DOI: 10.1016/ j.tripleo.2005.02.072.

3. Dourado E, Gomes AC, Silva ED, et al. Surgical removal of metallic foreign body in face: case report. Odontol Clín Client 2008;7(2):161-164.

4. Aniece C, Parmod K, Sanjeet S, et al. Foreign body in the Wharton's duct, a case report. JK Sci 2005;7:61-62.

5. Passi S, Sharma N. Unusual foreign bodies in the orofacial region. Case Rep Dent 2012. 191873. DOI: 10.1155/2012/191873.

6. Rangeeth BN, Moses J, Reddy NV. Self-injurious behavior and foreign body entrapment in the root canal of a mandibular lateral incisor. J Indian Soc Pedodont Prevent Dent 2011;29(6):95-98. DOI: 10.4103/0970-4388.90754.

7. Puliyel D, Balouch A, Ram S, et al. Foreign body in the oral cavity mimicking a benign connective tissue tumor. Case Rep Dent 2013;2013:369510. DOI: 10.1155/2013/369510.

8. Aregbesola SB, Ugboko VI. Unusual foreign bodies in the orofacial soft tissue spaces: a report of three cases. Niger J Clin Pract 2013;16(3): 381-385. DOI: 10.4103/1119-3077.113469.

9. Gaitonde PR, Davies AS. Foreign body in the floor of the orbit. Br J Oral Maxillofac Surg 2000;4(38):404-405. DOI: 10.1054/bjom.1999.0241.

10. Cameron M, Phillips B. Snookered! Facial infection secondary to occult foreign body. Int J Oral Maxillofac Surg 2006;35(4):373-375. DOI: 10.1016/j.ijom.2005.09.010.

11. Oikarinen KS, Nieminen TM, Mäkäräinen $\mathrm{H}$, et al. Visibility of foreign bodies in soft tissue in plain radiographs, computed tomography, magnetic resonance imaging, and ultrasound: an in vitro study. Int J Oral Maxillofac Surg 1993;22(2):119-124. DOI: 10.1016/s09015027(05)80818-5.

12. Krimmel M, Cornelius CP, Stojadinovic $S$, et al. Wooden foreign bodies in facial injury: a radiological pitfall. Int J Oral Maxillofac Surg 2001;30(5):445-447. DOI: 10.1054/ijom.2001.0109.

13. Hunter TB, Taljanovic MS. Foreign bodies. Radiographics 2003;23(3):731-757. DOI: $10.1148 /$ rg. 233025137.

14. O'Brien DP, Fantasia JE, Miller AS. Unusual foreign body presenting as a palatal tumor: Case report. Pediatr Dent 1988;10(3):226-227.

15. Price C, Whitehead Fl. Impression materials as foreign bodies. Br Dent J 1972;133(1):9-14. DOI: 10.1038/sj.bdj.4802872.

16. Arbona N, Jedrzynski M, Frankfather R, et al. Is glass visible on plain radiographs? a cadaver study. J Foot Ankle Surg 1999;38(4):264-270. DOI: 10.1016/s1067-2516(99)80068-4.

17. Marggraf E. A direct technique with a double lateral bridging flap for coverage of denuded root surface and gingiva extension: clinical evaluation after 2 years. J Clin Periodontol 1985;12(1):69-76. DOI: 10.1111/j.1600-051x.1985.tb01355.x.

18. Robinson PD, Rajayogeswaran V, Orr R. Unlikely foreign bodies in unusual facial sites. Br J Oral Maxillofac Surg 1997;35(1): 36-39. DOI: 10.1016/s0266-4356(97)90006-1. 